\title{
Anatomical location dictating major surgical complications for intradural extramedullary spinal tumors: a 10-year single-institutional experience
}

\author{
Clinical article
}

\author{
Ankit I. Mehta, M.D., ${ }^{1}$ Owoicho Adogwa, M.D., M.P.H., ${ }^{1}$ IsaAC O. KariKari, M.D., ${ }^{1}$ \\ Paul Thompson, B.S.E., 1 Terence Verla, M.P.H., ${ }^{1}$ Ulysses T. Null, B.S., ${ }^{1}$ \\ Allan H. Friedman, M.D., ${ }^{1}$ Joseph S. Cheng, M.D., M.S., ${ }^{2}$ Carlos A. Bagley, M.D., ${ }^{1}$ \\ AND Robert E. ISAACS, M.D. ${ }^{1}$ \\ ${ }^{1}$ Division of Neurosurgery, Department of Surgery, Duke University Medical Center, Durham, North \\ Carolina; and ${ }^{2}$ Department of Neurosurgery, Vanderbilt University Medical Center, Nashville, Tennessee
}

Object. Intradural extramedullary (IDEM) neoplasms are uncommon lesions that can pose a challenge for resection. Numerous factors affect the resectability and ultimately the outcome of these lesions. The authors report their 10-year institutional experience with the resection of IDEM neoplasms, focusing on the effect of location on surgical outcomes.

Methods. The authors performed a retrospective review of 96 consecutive patients who presented with a cervical and/or thoracic IDEM tumor that was resected between February 2000 and July 2009. All patients underwent MRI, and the axial location of the tumor was categorized as anterior, posterior, or lateral. Postoperative complications were assessed, as was neurological status at the patient's last follow-up clinic visit. Major complications assessed included CSF leakage requiring lumbar drainage, reexploration for epidural hematoma, and major postoperative neurological deficits.

Results. The mean \pm SD age at presentation was $51.16 \pm 17.87$ years. Major surgical approach-related complications occurred in $15 \%$ of patients. Major non-approach related surgical complications occurred in $7.1 \%$ of patients, while minor complications occurred in $14.2 \%$ of patients. Postoperative neurological deficits occurred most commonly in the thoracic spine between T-1 and T-8. Based on axial spinal cord location, the surgery-related complications rates for all anterior tumors $(n=12)$ was $41.6 \%$, whereas that for all lateral tumors $(n=69)$ was $4.4 \%$ and that for all posteriorly located tumors $(n=17)$ was $0 \%$.

Conclusions. Spinal IDEM tumors that are anteriorly located in the upper thoracic spine were found to have the highest rate of surgery-related complications and postoperative neurological deficits. This finding may be associated with the unforgiving anatomy of the upper thoracic spine in which there is a higher cord-to-canal ratio and a tenuous vascular supply.

(http://thejns.org/doi/abs/10.3171/2013.9.SPINE12913)

$\begin{array}{lllll}\text { Key WoRds } & \bullet \quad \text { extramedullary spinal tumor } \\ \text { schwannoma } & \bullet & \text { oncology }\end{array}$

$\mathrm{S}$ PINAL intradural extramedullary (IDEM) tumors account for two thirds of all primary intraspinal neoplasms, but these lesions are uncommon, with a reported incidence of 3-10 per 100,000 people..$^{3,5,14,20}$ In the adult population, the most common IDEM tumors arise from the nerve sheath (approximately 30\%) and from the meninges (approximately 25\%). ${ }^{8-10}$ The clinical presentation of IDEM tumors is determined in part by the location of the tumor, and in nearly all clinical instances radicular pain is the predominant presenting symptom, and, less

$$
\begin{aligned}
A b b r &
\end{aligned} \text { lary. }
$$

Abbreviation used in this paper: IDEM = intradural extramedul- commonly, motor deficits are present when the lesion is diagnosed later in the clinical course. In a recent study, Raco and colleagues ${ }^{15}$ reported that pain was the most common presenting symptom in approximately $72 \%$ of the patients they studied; this symptom was followed in frequency by motor disturbance in $55 \%$ and sensory loss in $39 \%$. Several authors have reported similar findings..$^{2-5}$

The majority of these lesions are benign (WHO Grades I and II), and patients usually benefit from surgical decompression and resection. Despite advances in operative techniques and neuroimaging, the morbidity associated with the resection of IDEM tumors continues to be significant. ${ }^{1}$ While intraoperative spinal cord monitor- 
ing (electromyography, motor evoked potentials, and somatosensory evoked potentials) has allowed surgeons to predict postoperative morbidity, it has done little to prevent postoperative complications. ${ }^{2}$ To avoid neurological complications associated with the resection of IDEM tumors, minimizing spinal cord manipulation is of utmost importance. $^{2}$

The authors of numerous published studies have described optimal surgical approaches that limit intraoperative spinal cord manipulation;, ;,6,21 despite this, there has been no systematic review of complications associated with both spinal cord level and axial location of IDEM tumors. Given the paucity of published studies assessing the impact of spinal column level and axial tumor location on the incidence of postoperative complications, we sought out to investigate the impact of tumor location, based on the preoperative MRI, on postoperative surgery-related complications.

\section{Methods}

\section{Patient Selection}

Institutional review board approval was obtained prior to commencement of this study. Ninety-six consecutive patients with a confirmed diagnosis of an IDEM tumor resected at Duke University Medical Center, between February 2000 and July 2009, were included in this series. Three senior surgeons in our group (R.I., A.F., and C.B.) performed all resections. Patient demographics, clinical presentation, comorbidities, tumor histological features and location, radiological studies, and all operative variables were reviewed for each case. All tumor specimens were reviewed by a neuropathologist and were classified according to the 1993 WHO classification system. We obtained follow-up data through a combination of clinical evaluations and reports from local physicians. The duration of follow-up was determined from the date of initial surgery to the last documented follow-up visit.

\section{Clinical Evaluation}

Preoperative evaluation consisted of a history of presenting illness, physical examination, and radiographic studies. Ambulatory status was recorded on admission and patients were stratified into 1 of 3 groups: 1) nonambulatory, 2) ambulatory with gait instability, and 3) ambulatory without problems. All patients included in this study had preoperative images (MR images) with an axial slice demonstrating the tumor and the respective spinal column level of the lesion. The axial MR images were assessed for location of tumor with respect to the spinal cord and were described to a correlate with a clock face. The tumors that were predominantly between " 10 and 2 o'clock" were considered "anterior," those that were either mainly "2 to 4 o'clock" or "8 to 10 o'clock" were considered "lateral," and those that were from "4 to 8 o'clock" were considered "posterior."

\section{Radiographic Examination}

Diagnostic evaluations included MRI, axial CT scanning, and plain myelography; the axial location of the tumor was categorized as anterior, posterior, or lateral.
On MRI, meningiomas appear as solid, well-circumscribed lesions attached to the dura mater. The tumor is iso- to hypointense on T1-weighted MR images and slightly hyperintense on T2-weighted FLAIR images. Meningiomas display intense homogeneity with contrast enhancement. A schwannoma appears as a solid tumor with associated displacement of the spinal cord, conus medullaris, or filum terminale. The majority of schwannomas appear isointense compared with the spinal cord on T1weighted MR images and hyperintense on T2-weighted FLAIR images. Contrast enhancement varies from intense homogeneous to faint enhancement, especially if a cystic component is present. Neurofibromas appear as fusiform or rounded tumors that are typically isointense on T1-weighted images and hyperintense on T2-weighted FLAIR images. Intense enhancement is usually seen postcontrast.

\section{Clinical Management}

The initial therapy was surgery in all cases. The goal of surgery in all cases was to achieve a gross-total resection while minimizing intraoperative spinal cord manipulation. The majority of patients underwent classic posterior laminectomies, with 1 patient undergoing a transpedicular decompression. For ventrally located tumors, the laminectomy was extended laterally toward the articular process to provide sufficient exposure and to facilitate a gross-total resection. After dural opening, a plane was developed between the arachnoid membrane and tumor surface. The tumor was then internally debulked using suction, an ultrasound surgical aspirator, laser, or microscissors. After internal debulking, the tumor was rolled away from the spinal cord and toward its dural attachment. Dura with residual tumor was either resected or coagulated using bipolar cauterization. In our series, the dural attachment was cauterized in the majority of cases. Primary dural closure was adequate and grafts were infrequently used. Steroids were not used postoperatively in any patient.

The extent of surgery was assessed according to the operative chart and the contrast-enhanced postoperative $\mathrm{CT}$ or MR images. The degree of resection was characterized as gross-total resection, debulked $(>75 \%$ reduction in tumor size), or partial resection (25\%-75\% reduction). In cases in which operative reports and neuroimaging findings differed, the degree of resection was based on imaging results. Additionally, 5 patients (5.2\%) underwent postoperative radiotherapy for recurrent tumors.

\section{Complication Classification}

All postoperative complications were assessed as was neurological status at the last follow-up clinic visit. Complications were categorized as 1 of the following: 1) major surgical approach-related complications, 2) major non-approach related complications, and 3) minor complications. Major surgical approach-related complications included: 1) CSF leakage requiring lumbar drainage, 2) reexploration for epidural hematoma, and 3) major postoperative neurological deficits. Major non-approach related complications included pulmonary edema, atrial fibrillation, cecal volvulus requiring exploratory laparotomy, and seizure activity. Minor complications included 


\section{Anatomical location and resection of IDEM tumors}

urinary tract infections, ileus, hyperglycemia requiring an insulin drip, medication-induced delirium, penicillin anaphylaxis, pruritis, and blood transfusion.

\section{Statistical Analysis}

Parametric data are presented as mean \pm SD and were compared via the Student t-test. Nonparametric data are given as median with the interquartile range and were compared using the Mann-Whitney U-test. Nominal data were compared with the chi-square test. A value of $\mathrm{p}<0.05$ was considered statistically significant. Time to tumor recurrence was graphically represented as estimated Kaplan-Meier plots, and a value of $p<0.05$ was considered statistically significant. Variables trending or significantly associated with major postoperative complications in the univariate regression analysis $(\mathrm{p}<0.10)$ were entered into a multiple logistic regression model to identify the independent predictors of major surgical approach-related and non-approach related complications. Stepwise multiple regression was performed to identify all variables that were independently associated a major postoperative complication $(\mathrm{p}<0.05)$.

\section{Results}

\section{Patient Cohort}

Ninety-six patients presenting with IDEM tumors were enroll in the study. There were 41 patients with meningioma, 31 with schwannoma, and 17 with neurofibroma. Four patients had arachnoid cysts and 3 had dermoid/ epidermoid tumors. No patients were excluded from our series. There was no association between tumor type and postoperative complication rates. The most common levels involved were occiput-C3 $(n=22)$ and T1-4 $(n=21)$ (Fig. 1). Eleven patients $(11.46 \%$ ) had a confirmed diagnosis of neurofibromatosis Type II; of these patients 10 (10.42\%) had a tumor recurrence. The mean age at presentation was $51.16 \pm 17.87$ years (54 women and 42 men) (Table 1$)$.

\section{Mode of Presentation}

The most frequent presenting symptoms were back pain and radicular pain (77.08\%), followed by sensory changes $(67.71 \%)$ and muscle weakness $(67.71 \%)$. Fortythree patients $(44.79 \%)$ reported problems with ambulation, and 17 patients $(17.71 \%)$ were nonambulatory. Bowel and bladder dysfunction was present in 19 (19.79\%) and 20 $(20.83 \%)$ patients, respectively.

\section{Tumor Location}

Figure 1 provides a summary of IDEM tumor location. Of the 96 tumors, $60(62.5 \%)$ were in the thoracic region. The remaining 36 tumors $(37.5 \%)$ were located in the cervical spine; of these, the majority were located in the high cervical region. There were no lesions involving the lumbar spine. Of the 96 IDEM tumors, $12(12.5 \%)$ were located anterior to the spinal cord, while $17(17.70 \%)$ and $67(69.79 \%)$ were located posterior and lateral to the spinal cord, respectively. No tumor had an extradural component.

\section{Overall Complication Rate}

There were 30 complications (31.25\%). Seventy-seven patients $(80.2 \%)$ had no complications in the perioperative period. The mean length of hospital stay following surgery for the cohort of patients with no perioperative complication was $4.2 \pm 1.2$ days, compared with $8.7 \pm 4.08$ days for the cohort that had at least 1 perioperative complication ( $\mathrm{p}=0.0004)$ (Fig. 2). In the cohort of patients with complications, those with an anteriorly located tumor had a higher overall complication rate $(33.4 \%)$ than those with a laterally or posteriorly located tumor $(17.9 \%$ and $17.7 \%$, respectively; $\mathrm{p}=0.002$ ). In a univariate analysis, we observed no correlation between operating surgeon and incidence of postoperative complication rates.

\section{Outcome After Surgery}

The mean duration of follow-up was $3.05 \pm 2.53$ years. Overall functional improvement was achieved in 87 cases $(90.6 \%)$. Three patients $(3.12 \%)$ reported being worse, and $6(6.25 \%)$ reported no functional improvement. Even patients with severe preoperative neurological deficits experienced full neurological recovery after careful surgical intervention and appropriate rehabilitation. Overall, the majority of patients postoperatively were ambulatory $(96.66 \%)$, whereas before surgery $82.29 \%$ were able to walk $(\mathrm{p}=0.035)$. No improvement occurred in 4 patients. Of the 65 patients presenting with preoperative weakness, $2(2.08 \%)$ reported being worse, while 63 (96.92\%) experienced complete resolution of the preoperative deficits.

All patients $(n=19)$ with bowel dysfunction preoperatively exhibited normal function after surgery. Of the 20 patients with bladder dysfunction preoperatively, 17 (85\%) reported normal bladder control at follow-up examination. Overall, $10.42 \%$ of patients experienced tumor recurrence, which most commonly occurred in the thoracic region ( $p$ $=0.02$ ). The median duration of time to tumor recurrence was 3 years (IQR 1-4.7 years) (Fig. 3).

\section{Major Surgery-Related Complications}

The surgery-related complication rates were higher $(41.6 \%)$ in patients presenting with anterior tumors $(\mathrm{n}=$ 12) than in those presenting with lateral tumors $(n=69)$ or posterior tumors $(n=17)(4.4 \%$ and $0 \%$, respectively) of (Tables 2 and 3). The incidence of major surgery-related complications was highest in the thoracic spine (Table 3). No statistically significant difference was observed in the frequency of tumor occurrence between anatomical levels of the spine $(\mathrm{p}=0.980)$ (Table 3).

Postoperative neurological (motor/sensory) deficits were observed in 3 patients, all of whom had anteriorly located IDEM tumors. All major postoperative neurological deficits occurred in the thoracic spine between T-1 and T-8 (9.5\% at T1-4 and 5\% at T5-8). The mean length of hospital stay following surgery in the cohort of patients experiencing at least 1 major surgically related postoperative complication was $13.2 \pm 3.70$ days $(\mathrm{p}=0.005 ; 14$ days for those with a CSF leak; 19 days for those requiring reexploration for epidural hematoma; and 11.6 days those with a major postoperative neurological deficit). All 3 patients with postoperative neurological deficits had experienced no improvement by last clinic follow-up visit. 


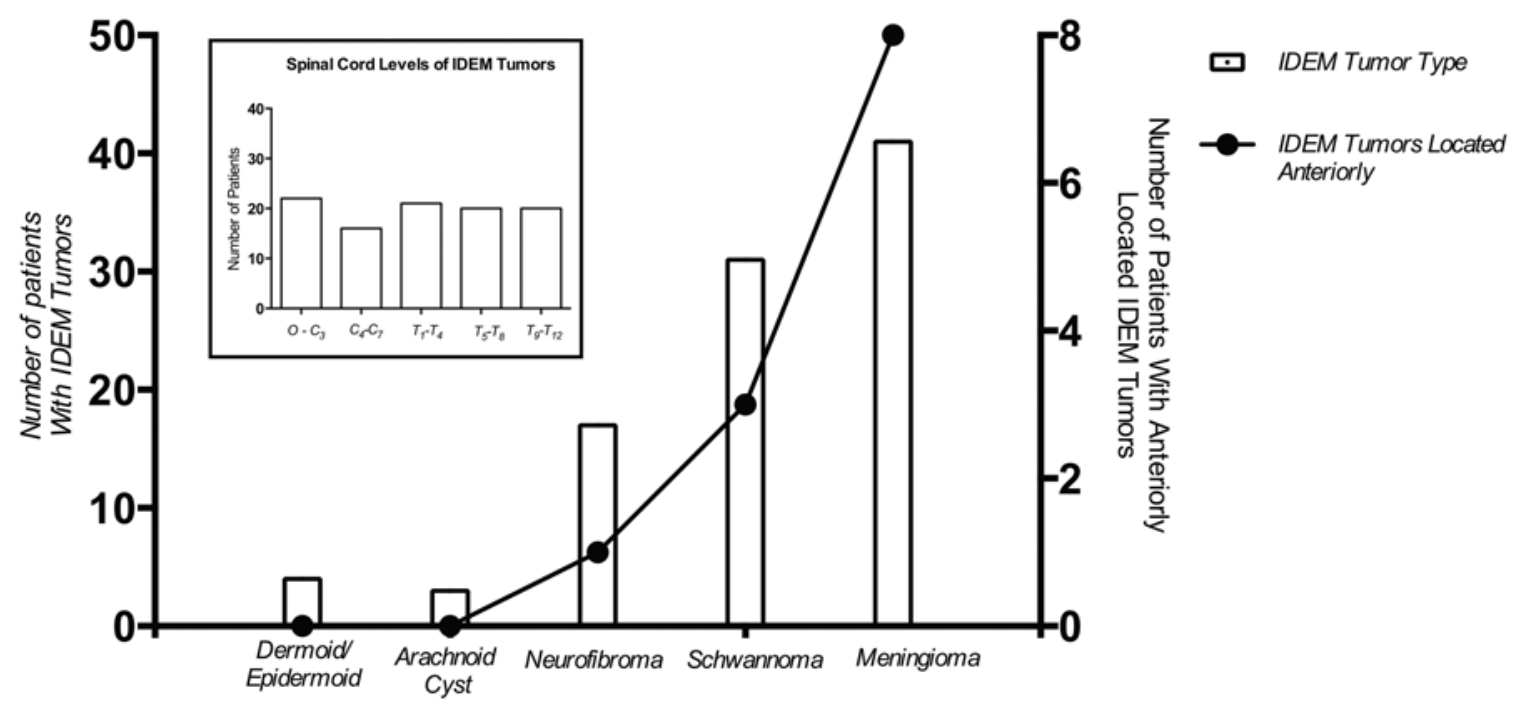

FIG. 1. Graph demonstrating the number of patients with each IDEM tumor subtype and the number of anteriorly located tumors in each IDEM tumor subgroup. Meningioma was the most common IDEM tumor, occurring in $43 \%$ of patients. The number of IDEM tumors anteriorly located ranged from 0 in the dermoid/epidermoid cohort to 8 in the meningioma cohort. The most common levels involved were occiput-C4 $(n=22)$ and T1-4 $(n=21)$.

\section{Major Non-Approach Related Surgical Complications}

Overall major non-approach related complications occurred in $7.1 \%$ of patients who underwent surgical resection for IDEM tumors. Major non-approach related complications included pulmonary edema (3.1\%), atrial fibrillation $(1.0 \%)$, cecal volvulus requiring exploratory laparotomy (1.0\%), and seizure activity (2.0\%). Overall, the mean length of hospital stay was $9.7 \pm 2.0$ days $(10.3 \pm$ 1 days for those with pulmonary edema; 14 days for those with atrial fibrillation; 12 days for those with cecal volvulus requiring exploratory laparotomy; and $5.5 \pm 0.71$ days for those with seizures; Table 4).

\section{Minor Complications}

Minor complications were documented in $14.2 \%$ of patients in the perioperative period following tumor resection. Minor complications included urinary tract infections $(5.1 \%)$, ileus (3.1\%), hyperglycemia requiring an insulin drip (2.0\%), medication-induced delirium (1.0\%), penicillin anaphylaxis $(1.0 \%)$, pruritis $(1.0 \%)$, and blood transfusion $(1.0 \%)$. Overall, the mean length of hospital stay for patients with minor complications was $6.83 \pm 2.24$ days (Table 5).

\section{TABLE 1: Baseline characteristics of 96 patients with IDEM} tumors

\begin{tabular}{lc}
\hline \multicolumn{1}{c}{ Characteristic } & Value \\
\hline mean age in yrs & $51.16 \pm 17.87$ \\
no. of males (\%) & $42(44)$ \\
mean days of hospital stay & $5.11 \pm 2.82$ \\
tumor location (\%) & \\
cervical & $36(37.5)$ \\
thoracic & $60(62.5)$ \\
\hline
\end{tabular}

Correlation Between IDEM Tumor Location and Postoperative Complication

In a univariate analysis, patient age, sagittal and ventral tumor location, ambulatory status, bowel dysfunction, bladder dysfunction, muscle weakness, pain, and sensory disturbance were all associated with an increased likelihood of a major postoperative complication. When included in a multivariate logistic regression model, a ventral tumor located in the upper thoracic region was independently associated with an increased likelihood of a major postoperative complication (Table 6).

\section{Discussion}

Patients presenting with ventrally located IDEM tumors $(\mathrm{p}=0.0051)$ in the upper thoracic spine (T1-4) (p $=0.005)$ were found to have the highest rate of major surgery-related complications. In this 10-year retrospective study, surgery was shown to be clinically effective in the majority of patients with IDEM tumors. Furthermore, while most patients experienced a significant improvement in functional outcomes, extra precaution should be taken in cases in which IDEM spinal tumors are locat-

TABLE 2: Major surgical approach-related complication rate in patients with an axial tumor location*

\begin{tabular}{lccc}
\hline \multirow{2}{*}{ Major Complication } & \multicolumn{3}{c}{ IDEM Tumor Location (\%) } \\
\cline { 2 - 4 } & Anterior & Lateral & Posterior \\
\hline postop bleed & 8.3 & 2.9 & 0 \\
postop neurological deficits & 25 & 0 & 0 \\
CSF leak & 8.3 & 1.5 & 0 \\
total complications & 41.6 & 4.4 & 0 \\
\hline * Anteriorly located tumors are associated with a high major surgical \\
approach-related complication rate.
\end{tabular}




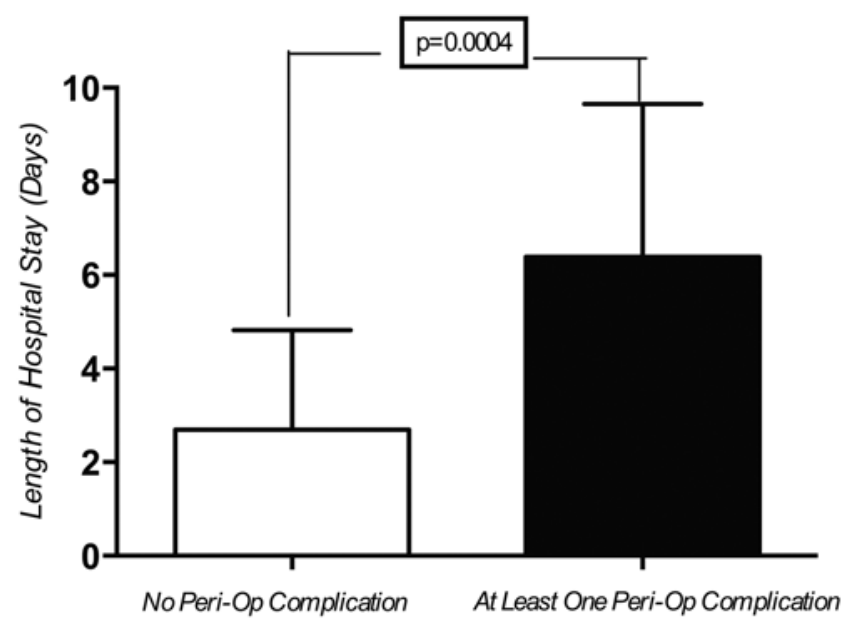

FIG. 2. Graph showing mean length of hospital stay following surgery: $4.2 \pm 1.2$ days versus $8.7 \pm 4.08$ days in the cohort of patients with no perioperative complication and the cohort with at least 1 perioperative complication, respectively $(p=0.0004)$. The anteriorly located IDEM tumor group had a higher overall complication rate.

ed in the anterior upper thoracic spine, as patients with these lesions are at a significantly elevated risk of having a major surgery-related complication. To our knowledge, this is the first systematic study assessing the association between axial/sagittal tumor location and outcomes and postoperative complication rates.

The association between ventral tumor location and surgical outcome has been previously published. Slin'ko and colleagues have demonstrated that the more proximal the location of a tumor and the more ventral the tumor was to the spinal cord, the worse the surgical outcome and greater the likelihood of having a postoperative neurological deficit. ${ }^{18}$ Conversely, Ahn and colleagues 3 found no association between ventral tumor location and poor outcomes. Thus, the prognostic value of a ventral tumor location remains unclear. Analogous to the findings of Slin'ko and colleagues, we observed that anteriorly located spinal cord tumors trended toward development of neurological deficit, although the trend not significant $(\mathrm{p}=0.092)$. However, a sagittal spinal column level was significantly associated with the development of a neurological deficit $(p=0.01)$, as patients with IDEM tumors located in the rostral thoracic spine were more likely to have a postoperative neurological deficit. The finding of higher complication rates for anteriorly located upper thoracic tumors may be related to the unforgiving anatomy of the upper thoracic spine, which has a higher cord-to-canal ratio, as well as the tenuous vascular supply to that region of the spinal cord. This finding highlights the importance taking additional precautionary measures to mitigate the risk of major complications when resecting anteriorly located upper thoracic IDEM spinal cord tumors.

In our study, a posterior or posterolateral approach was used primarily (>97\% of cases), regardless of the location of the tumor relative to the spinal cord. Slin'ko and colleagues suggested that an extreme lateral or anterior approach was necessary for resection of ventrally located tumors. ${ }^{18}$ However, Ahn and colleagues in a retrospec-

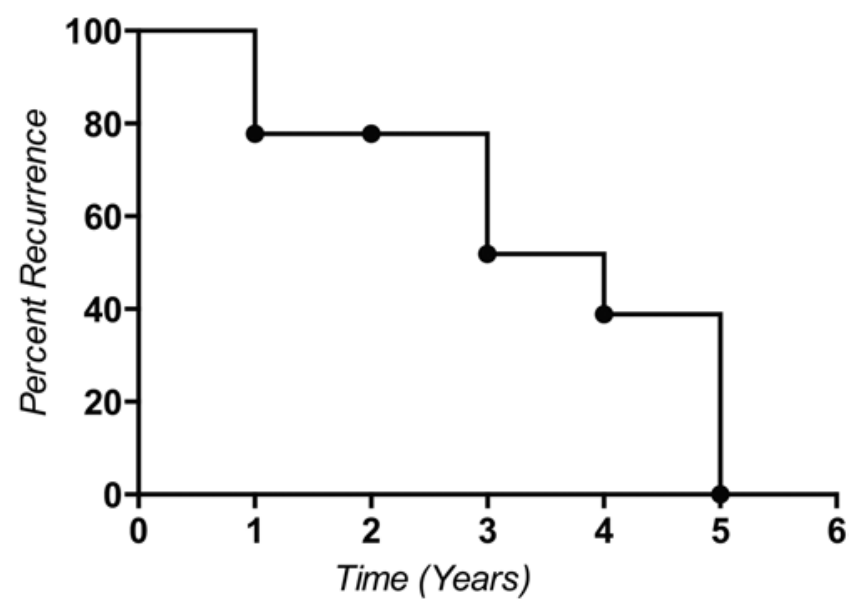

Fig. 3. Kaplan-Meier plot depicting the duration of time to tumor recurrence. The median for time to tumor recurrence was 3 years (IQR $1-4.75$ years).

tive study of patients that underwent surgical resection of IDEM tumors via a posterior approach, reported no difficulties in removing ventrally located IDEM tumors. ${ }^{3}$ Furthermore, these authors suggest that extreme lateral or anterior approaches might not be necessary. Analogous to the findings by Ahn and colleagues, we experienced no difficulty in resecting ventrally located tumors via a posterior or posterolateral approach. While we agree that the extreme-lateral or anterior approach might be necessary in cases in which patients present with severe spinal canal stenosis due to a ventrally located IDEM tumor, we feel less inclined to use the extreme-lateral or anterior approach for all ventrally located spinal tumors.

Numerous studies have shown a positive association between gross-total resection and favorable outcomes. ${ }^{4,5,8,10,14,16,18,19}$ Slin'ko and colleagues reported complete resection in $74 \%$ of their cases, with subtotal and partial resection achieved in $21 \%$ and $5 \%$, respectively. ${ }^{18}$ They noted a lower recurrence rate in patients who underwent gross-total resection. Similarly, Gottfried and colleagues achieved complete resection in $92 \%$ of their cases. ${ }^{8}$ They reported that patients who underwent grosstotal resection were more likely to remain disease free than patients who underwent partial or subtotal resection. Other authors have reported that gross-total resection was the most important treatment variable influencing long-term outcomes and recurrence rates in patients with IDEM tumors. ${ }^{3,10,13,19}$ In the current series, gross-total re-

TABLE 3: Major surgical approach-related complication rate in patients with a sagittal tumor location*

\begin{tabular}{lccccc}
\hline \multicolumn{1}{c}{ Major Complication } & Occiput-C3 & C4-7 & T1-4 & T5-8 & T9-12 \\
\hline postop bleed (\%) & 0 & 0 & 9.5 & 0 & 0 \\
neurological deficit (\%) & 0 & 0 & 9.5 & 5 & 0 \\
CSF leak (\%) & 4.5 & 0 & 4.7 & 0 & 0 \\
total complications (\%) & 4.5 & 0 & 23.7 & 5 & 0 \\
\hline
\end{tabular}

* Upper thoracic tumors were associated with a high major surgical approach-related complication rate. 


\section{A. I. Mehta et al.}

TABLE 4: Major non-surgical approach related complications and length of hospital stay

\begin{tabular}{lcc}
\hline \multicolumn{1}{c}{ Major Complication } & $\begin{array}{c}\text { Average No. of } \\
\text { Postop Days }\end{array}$ & $\begin{array}{c}\text { No. of } \\
\text { Complications } \\
(\%)\end{array}$ \\
\hline pulmonary edema & 10.3 & $3(3.1)$ \\
seizure & 5.5 & $2(2.0)$ \\
atrial fibrillation & 14 & $1(1.0)$ \\
cecal volvulus requiring exploratory & 12 & $1(1.0)$ \\
$\quad$ laparotomy & & \\
total no. of complications & & $7(7.1)$ \\
\hline
\end{tabular}

section was attempted in every patient but was achieved in $90 \%$ of cases, with subtotal resection and partial resection in 7\% and 3\% of cases, respectively. The incidence of tumor recurrence was significantly higher in patients who underwent a subtotal or partial resection $(p=0.04)$. Notably, achieving a gross-total resection was associated with a minimal increase in the complication rate; however, this relationship was not statistically significant. This finding suggests that gross-total resection is important for achieving short- and long-term symptomatic relief and is pivotal for preventing tumor recurrence.

Recurrence of IDEM spinal tumors was rare, occurring in $11 \%$ of cases in our series. This is consistent with other series in which the recurrences rate ranged from $0 \%$ to $12 \%$. In reviewing their own data and those reported in 6 large series in the literature, Gottfried and colleagues noted complete resection in $82 \%-99 \%$ of cases and reported a tumor recurrence rate of $4 \% .{ }^{8}$ The authors reported a mean time to tumor recurrence of 2 years. Klekamp and Samii reported a recurrence rate of $14.7 \% .^{11,12} \mathrm{Simi}-$ larly, Gezen and colleagues reported a tumor recurrence rate of $5.6 \%$, with a mean time to recurrence of 5-8 years. Other authors have reported IDEM tumor recurrence rates ranging from $1.3 \%$ to $17.7 \%$, with time to recurrence ranging from 1 to 17 years. ${ }^{8}, 11,13,15,17,20$ Consistent with these aforementioned studies, we observed a recurrence rate of $11 \%$, with a mean time to tumor recurrence of $2.89 \pm 1.83$ years. There was no statistically significant difference in tumor recurrence rates between patients who underwent radical dural resection and those who underwent dural coagulation $(\mathrm{p}=0.87)$. Additionally, we observed no differ-

\section{TABLE 5: Incidence of minor non-surgical approach related} complications

\begin{tabular}{lc}
\hline \multicolumn{1}{c}{ Minor Complication } & No. of Complications (\%) \\
\hline urinary tract infection & $5(5.1)$ \\
ileus & $3(3.1)$ \\
hyperglycemia/insulin drip & $2(2)$ \\
medication-induced delirium & $1(1)$ \\
penicillin anaphylaxis & $1(1)$ \\
pruritus & $1(1)$ \\
blood transfusion & $1(1)$ \\
total no. of complications & $14(14.2)$ \\
\hline
\end{tabular}

TABLE 6: Independent preoperative predictors of a major postoperative complication

\begin{tabular}{lcc}
\hline Independent Variable & Coefficient & p Value \\
\hline patient age & -0.60 & 0.72 \\
sagittal tumor location & 4.03 & 0.01 \\
ventral tumor location & 2.12 & 0.05 \\
ambulatory problems & 2.43 & 0.32 \\
bowel dysfunction & 20.19 & 0.98 \\
bladder dysfunction & 15.45 & 0.74 \\
muscle weakness & 0.83 & 0.32 \\
sensory disturbance & -0.35 & 0.68 \\
pain & -0.32 & 0.69 \\
\hline
\end{tabular}

ence in tumor recurrence rates between older and younger patients. In our patients, the mean age at the time of recurrence was $34 \pm 17.4$ years.

Intradural extramedullary tumors accounts for $65 \%$ of all primary spinal cord tumors, of which $15 \%-51 \%$ are meningiomas. ${ }^{3,5,9,16}$ Several authors have reported similar findings. ${ }^{13,18}$ Spinal meningiomas occur most frequently in middle-aged women. Cohen-Gadol et al. reported a 7:1 female/male ratio in their series of patients who underwent resection of spinal cord meningiomas. ${ }^{5}$ Solero and colleagues suggested that spinal meningiomas occurred more frequently in women because of a possible dependence on sex hormones..$^{19}$ Several authors have reported similar findings. Consistent with previously published studies, $57 \%$ of patients in the current series were middleaged women.

The limitations inherent in our study have implications for its interpretation. We were concerned that a biased sampling of tumors could provide an overrepresentation of tumors in a subgroup. However, the tumor distribution within each spinal sagittal level (0.98) was equal among all subcategories. Our data are further validated by the fact that major non-approach related and minor complications were not correlated with location. Therefore, we can infer that major surgically related complications are associated with both a sagittal and axial location of the tumor. Furthermore, the lack of a nonoperative control group precludes any comparison with other available treatment modalities. Despite these limitations, our study demonstrates that although resection of IDEM tumors resulted in improved functional outcomes, patients with anteriorly located upper thoracic were at an elevated risk of experiencing a major surgery-related postoperative complication.

\section{Conclusions}

Spinal IDEM tumors that are anteriorly located in the upper thoracic spine were found to have the highest rate of surgery-related complications and postoperative neurological deficits. This finding might be associated with the unforgiving anatomy of the upper thoracic spine, with a higher cord-to-canal ratio, as well as the tenuous vascular supply to that region of the spinal cord. 


\section{Anatomical location and resection of IDEM tumors}

\section{Disclosure}

Dr. Isaacs holds a patent at NuVasive; has received clinical or research support for the study from NuVasive and OREF; has direct Stock ownership in Baxano, VillaMed, LLC, and VillaSpine, LLC; and is a consultant for NuVasive, Baxano, and DePuy. The other authors report no conflict of interest concerning the materials or methods used in this study or the findings specified in this paper.

Author contributions to the study and manuscript preparation include the following. Conception and design: Mehta, Friedman, Cheng, Bagley, Isaacs. Acquisition of data: Mehta, Adogwa, Karikari, Thompson, Bagley. Analysis and interpretation of data: Mehta, Adogwa, Karikari, Thompson, Verla, Toche, Bagley, Isaacs. Drafting the article: Mehta, Adogwa, Karikari, Thompson, Verla, Toche, Bagley, Isaacs. Critically revising the article: all authors. Reviewed submitted version of manuscript: all authors. Statistical analysis: Adogwa, Karikari, Thompson, Isaacs. Study supervision: Cheng, Isaacs.

\section{References}

1. Abul-Kasim K, Thurnher MM, McKeever P, Sundgren PC: Intradural spinal tumors: current classification and MRI features. Neuroradiology 50:301-314, 2008

2. Acosta FL Jr, Aryan HE, Chi J, Parsa AT, Ames CP: Modified paramedian transpedicular approach and spinal reconstruction for intradural tumors of the cervical and cervicothoracic spine: clinical experience. Spine (Phila Pa 1976) 32:E203E210, 2007

3. Ahn DK, Park HS, Choi DJ, Kim KS, Kim TW, Park SY: The surgical treatment for spinal intradural extramedullary tumors. Clin Orthop Surg 1:165-172, 2009

4. Angevine PD, Kellner C, Haque RM, McCormick PC: Surgical management of ventral intradural spinal lesions. Clinical article. J Neurosurg Spine 15:28-37, 2011

5. Cohen-Gadol AA, Zikel OM, Koch CA, Scheithauer BW, Krauss WE: Spinal meningiomas in patients younger than 50 years of age: a 21-year experience. J Neurosurg 98 (3 Suppl): 258-263, 2003

6. Gambardella G, Gervasio O, Zaccone C: Approaches and surgical results in the treatment of ventral thoracic meningiomas. Review of our experience with a postero-lateral combined transpedicular-transarticular approach. Acta Neurochir (Wien) 145:385-392, 2003

7. Gezen F, Kahraman S, Canakci Z, Bedük A: Review of 36 cases of spinal cord meningioma. Spine (Phila Pa 1976) 25: 727-731, 2000

8. Gottfried ON, Gluf W, Quinones-Hinojosa A, Kan P, Schmidt MH: Spinal meningiomas: surgical management and outcome. Neurosurg Focus 14(6):e2, 2003
9. Jenkinson MD, Simpson C, Nicholas RS, Miles J, Findlay GF, Pigott TJ: Outcome predictors and complications in the management of intradural spinal tumours. Eur Spine J 15:203210, 2006

10. King AT, Sharr MM, Gullan RW, Bartlett JR: Spinal meningiomas: a 20-year review. Br J Neurosurg 12:521-526, 1998

11. Klekamp J, Samii M: Surgical results of spinal meningiomas. Acta Neurochir Suppl 65:77-81, 1996

12. Klekamp J, Samii M: Surgical results for spinal meningiomas. Surg Neurol 52:552-562, 1999

13. Mirimanoff RO, Dosoretz DE, Linggood RM, Ojemann RG, Martuza RL: Meningioma: analysis of recurrence and progression following neurosurgical resection. J Neurosurg 62:1824, 1985

14. Papanagiotou P: [Extramedullary intradural spinal tumors.] Radiologe 51:1025-1031, 2011 (Ger)

15. Raco A, Esposito V, Lenzi J, Piccirilli M, Delfini R, Cantore G: Long-term follow-up of intramedullary spinal cord tumors: a series of 202 cases. Neurosurgery 56:972-981, 2005

16. Roux FX, Nataf F, Pinaudeau M, Borne G, Devaux B, Meder JF: Intraspinal meningiomas: review of 54 cases with discussion of poor prognosis factors and modern therapeutic management. Surg Neurol 46:458-464, 1996

17. Setzer M, Vatter H, Marquardt G, Seifert V, Vrionis FD: Management of spinal meningiomas: surgical results and a review of the literature. Neurosurg Focus 23 (4):E14, 2007

18. Slin'ko EI, Al-Qashqish II: Intradural ventral and ventrolateral tumors of the spinal cord: surgical treatment and results. Neurosurg Focus 17(1):ECP2, 2004

19. Solero CL, Fornari M, Giombini S, Lasio G, Oliveri G, Cimino C, et al: Spinal meningiomas: review of 174 operated cases. Neurosurgery 25:153-160, 1989

20. Song KW, Shin SI, Lee JY, Kim GL, Hyun YS, Park DY: Surgical results of intradural extramedullary tumors. Clin Orthop Surg 1:74-80, 2009

21. Steck JC, Dietze DD, Fessler RG: Posterolateral approach to intradural extramedullary thoracic tumors. J Neurosurg 81: 202-205, 1994

Manuscript submitted September 27, 2012.

Accepted September 3, 2013.

Please include this information when citing this paper: published online October 11, 2013; DOI: 10.3171/2013.9.SPINE12913.

Address correspondence to: Ankit I. Mehta, M.D., The Johns Hopkins Hospital, Meyer Building Room 5-109, 600 N. Wolfe St., Baltimore, MD 21287. email: amehta28@jhmi.edu. 